\title{
Chronic fatigue syndrome in childhood: seven-year follow-up study ${ }^{\dagger}$
}

\author{
Shakil S. Khawaja and Pieter Van Boxel
}

\begin{abstract}
This study explores the outcome and longer-term sequelas of suffering chronic fatigue syndrome in childhood. Ten such children, ranging from 10 to 16 years of age of diagnosis, were followed up into adulthood, an average of seven years. Most were completely well or markedly improved (seven of nine). Only children fully engaged in therapy made a fotal recovery. However, respondents felt medical staff did not believe their symptoms and that rehabilitative strategles were unhelpful. No physical or mental illness was subsequentty diagnosed to account for the originat symptom presentation. Chilchood sufferers maintained the same pattem of symptoms as adults. Depressive symptomatology was present in two cases. The overall longer-term prognosis for children suffering chronic fatigue syndrome is good. A successtul doctor-patient relationship is escential to improve compliance with management plans.
\end{abstract}

Chronic fatigue syndrome (CFS) remains a subject of much heated debate. The condition in children has led to particularly passionate representations of the views of the ME Association and affiliated groups, and the media. A report by the three Royal Colleges in 1996 highlights the need for urgent research into all aspects of CFS in childhood (Royal Colleges of Physicians, Psychiatrists and General Practitioners, 1996). This paper is useful because it reports on a longer follow-up period than the limited number of previous studies. Most areas of CFS in adults have been extensively investigated, including various follow-up studies (Bonner et al, 1994; Wilson et al, 1994). Much of the data on childhood outcome is extrapolated from adults or relates to isolated case reports. CFS can still cause major disruption to a child's education, peer relationships and family life (Harris \& Taitz, 1989).

CFS is a syndrome characterised by fatigue of definite onset which is severe, disabling and affects physical and mental functioning. It is not

'See editorial pp. 193-194 and 203-206, this issue. relieved by rest and has a minimum duration of six months. There must be substantial functional impairment. Exclusion criteria include underlying physical conditions known to cause chronic fatigue and current psychiatric diagnoses of schizophrenia, manic-depressive illness, substance misuse, eating disorder or proven organic brain disease (Fukuda et al, 1994).

The purpose of this study was to explore the effects CFS may have on the developing child or adolescent individual and to examine the longerterm outcome of such children. This paper follows-up 10 children on average seven years after diagnosis of CFS. The original 10 were seen as consecutive referrals over a 12-month period by our psychiatric department at the Family and Young Persons' Unit, Reading. These case reports were published in April 1992 (Vereker, 1992).

All 10 families were initially averse to psychiatric involvement. The first interview was in a joint setting with a paediatrician, once physical pathology had been excluded. As is frequently the case in CFS, laboratory tests and physical examination were satisfactory (Kennedy \& Pearce, 1995). Once diagnosed the management plan was one which focused primarily on structured rehabilitative strategies, while supporting both the patient and family during the process. It was important to acknowledge the symptoms as being real. Baseline information was obtained by keeping a diary of activities. Patients were involved with goal setting. A behavioural approach was used with gradually increasing physical activities together with increased school attendance, leisure and social interaction. The cognitive emphasis was on dealing with possible perpetuating factors for the fatigue (such as illness beliefs, inactivity or inconsistent activity and emotional state) rather than aetiological factors (Wessely et al, 1989; Butler et al, 1991; David \& Wessely, 1993). We aimed to decrease any secondary gain. Early return to school was encouraged. These methods of graded exercise and cognitive restructuring have since been shown to be beneficial in two 
Table 1. Patient characteristics

\begin{tabular}{llllll}
\hline Case number & Gender & $\begin{array}{l}\text { Age at follow-up } \\
\text { (years) }\end{array}$ & $\begin{array}{l}\text { Age at onset } \\
\text { (years) }\end{array}$ & $\begin{array}{l}\text { Age when seen by } \\
\text { peychiatrist (years) }\end{array}$ & $\begin{array}{l}\text { Duration of symptoms } \\
\text { before seen (years) }\end{array}$ \\
\hline 1 & F & 22.4 & 13.4 & 14.5 & 1.1 \\
2 & F & 20.4 & 12 & 12.9 & 0.9 \\
3 & M & 20.1 & 10.3 & 10.5 & 0.3 \\
4 & F & 23.5 & 12.8 & 15.8 & 2.9 \\
5 & F & 22.5 & 14.2 & 14.6 & 0.4 \\
6 & F & 22.7 & 11.8 & 12.8 & 5 \\
7 & F & 24.1 & 11.4 & 16.4 & 1.2 \\
8 & M & 23.2 & 14.4 & 15.6 & 2.3 \\
9 & F & 22.7 & 12.5 & 14.8 & 1 \\
\hline 10 & F & 21.3 & 13 & 14 & \\
\hline
\end{tabular}

recently randomised controlled trials (Deale et al, 1997; Fulcher \& White, 1997).

\section{The study}

Information was gathered by two carefully constructed postal questionnaires. One was designed for the patient and his or her family, and the other for the patient's general practitioner. The areas covered included: (a) present symptomatology or disability in physical, psychological, and social spheres; (b) a measure of the severity of symptoms; (c) duration and course of illness; (d) other illness, including psychiatric or hospital admission in either patient or family: (e) views on aetiology: and (f) degree to which families engaged with psychiatric services. We were also interested in the patients' subjective views of return of confidence, effect of illness on education and usefulness of the rehabilitative scheme.

\section{Patient characteristics}

\section{Age and gender}

The ages ranged from 10.5 years to 16.4 years at first psychiatric interview. The mean age of onset was 12.6 years. The mean duration of symptoms prior to psychiatric referral was 1.6 years. The female to male ratio was 4:1 (see Table 1).

Physical symptoms

All patients fulfilled the diagnostic criteria for CFS.

Absence from school

All the children had significant periods away from school, ranging from half a term to two complete years.

\section{Individual characteristics}

All the children were of average intelligence. None had a history of developmental or learning difficulties, emotional or other behavioural problems.

\section{Findings}

Nine of the 10 patients were available for followup. One patient (case 7) had moved and left no forwarding address. She had made a good early recovery initially and remained asymptomatic 18 months later.

Another patient (case 6) refused to complete the questionnaire but did provide the information by telephone. She was presently symptomatic and had suffered severe symptoms for prolonged periods since diagnosis. Of the remaining eight, four patients were asymptomatic and four were symptomatic (see Table 2). The assessment of progress made by the general practitioner correlated well with the patient's own views.

\section{Characteristics of those patients presently asymptomatic}

All four asymptomatic patients had no residual symptoms. They all engaged in psychiatric services and participated in an active rehabilitation plan. Psychiatric involvement varied between three and 18 months. All had continued paediatric follow-up. There was no other relevant personal or family psychiatric or other medical history. The mean duration of illness before psychiatric interview was 15 months. On average, improvement was noted three months thereafter. The mean time off school was six months.

\section{Characteristics of those patients presently symptomatic}

Of the five symptomatic patients, all still had core symptoms. Two have had moderate to severe symptoms since diagnosis. Neither engaged with psychiatric services nor participated in a rehabilitation programme. They refused psychiatric involvement after only one session, and of the whole group had the longest time off school. Case 4 is now aged 21 years and left school aged 15. She lives with her parents, has 
Table 2. Results of present state and patient attitudes

\begin{tabular}{|c|c|c|c|c|c|}
\hline $\begin{array}{l}\text { Cose } \\
\text { number }\end{array}$ & Present state & $\begin{array}{l}\text { Engoged with poychiatic } \\
\text { services }\end{array}$ & $\begin{array}{l}\text { Full retum of } \\
\text { confidence }\end{array}$ & $\begin{array}{l}\text { Subjective efiect } \\
\text { on ecucation }\end{array}$ & $\begin{array}{l}\text { Usehulness of } \\
\text { rehobillitation } \\
\text { regime }\end{array}$ \\
\hline 1 & Recovered fully & Yes & Yes & Minimal & Minimal \\
\hline 2 & Very much improved & No & Yes & Minimal & None \\
\hline 3 & Recovered fully & Yes & Yes & Minimal & None \\
\hline 4 & Same or worse & No & No & Severe & None \\
\hline 5 & Very much improved & No & Yes & Severe & None \\
\hline 6 & Same or worse & No & No & Minimal & None \\
\hline 7 & - & - & - & - & - \\
\hline 8 & Recovered fully & Yes & Yes & None & None \\
\hline 9 & Recovered fully & Yes & Yes & Minimal & Minimal \\
\hline 10 & Very much improved & Yes & Yes & None & None \\
\hline
\end{tabular}

no partner and is unemployed. She requires a minimum of 14 hours sleep a day and is excessively fatigued by two hours of shopping. Case 5 is now aged 23 years. She also lives with her parents, has no partner and is employed part-time. She is unable to concentrate to read, cannot participate in sporting activities and has very limited social contact outside the home.

Of the remaining three patients, symptoms were present but regarded as very much improved. Only two of these patients had engaged in therapy and participated in rehabilitation. All three patients had a positive history of medical illness in a first-degree relative: one mother suffered with multiple sclerosis, another with diabetes mellitus and one father with epilepsy.

Of the four respondents who were symptomatic, two described depressive symptomatology and were being treated with antidepressants. One also described anxiety and panic attacks. Both felt that CFS had greatly affected their academic performance and limited their social contacts outside the home environment. Three of the four had sleep disturbance, mainly initial insomnia or difficulty in getting up on time.

\section{Patients' attitudes}

Flve of the eight respondents answered the questions on attitude to illness and treatment. All five (three symptomatic and two asymptomatic) felt that their symptoms were not believed. and that psychiatric involvement was unhelpful and unsympathetic. Only two of nine patients could ascribe any benefit from psychiatric referral.

Two believed their illness to be wholly physically based (both asymptomatic) and three that the illness was a mixture of physical and psychological problems (all were symptomatic). This does not reflect the findings of most prognostic studies, which correlate a strong belief that symptoms are solely due to a physical cause with poor outcome (Cleare \& Wessely. 1996).

\section{Comment}

The clinical impression is that CFS in childhood is rare, ranging in severity from mild to severe forms (David et al, 1988; Kennedy \& Pearce. 1995). Although becoming increasingly recognised, there are no community surveys determining prevalence in this age group (Lask \& Dillon. 1990). Its overall prevalence in primary care is estimated to be 0.5 to $1.5 \%$ (Wessely, 1995).

CFS in childhood follows a variable course. In our series of nine, four $(44 \%)$ were completely well, three (33\%) markedly improved and two (22\%) unimproved or worse. Feder et al (1994) described the outcome of severe CFS in childhood in an uncontrolled selective case series. They followed up 48 such children but for the shorter average period of 3.8 years. The outcome was good with $65 \%$ reporting resolution of symptoms, $29 \%$ improvement and $6 \%$ being unchanged. Pooling results from the four previous outcome studies of CFS in childhood, 54$94 \%$ of children will make a definite improvement or a complete recovery (Joyce et al, 1997). In our study the average follow-up period was twice that of Feder et al and suggests that the generally improved outcome in children is maintained over time.

Outcome studies of greater sample size have only been conducted in adults with CFS (Hinds \& McCluskey, 1993). Recent follow-up of 420 adults showed $31 \%$ were improving. 25\% were not improving, 24\% were deteriorating and 20\% were following a fluctuating course (Dowsett et al, 1990). Comparing these results, it would appear that although similar numbers of children and adults with CFS will improve, fewer adults will recover completely and more adults will have fluctuating, unimproved or worsening 
symptoms than children. Indeed, in their systematic review of the prognosis of CFS, Joyce et al report that in adults only a small minority of cases $(0-6 \%)$ recover to premorbid levels over the period of follow-up.

The greatest drawback of our series was its small sample size. The similarities between this and the previous studies of CFS in childhood were that; first, we used our own structured questionnaire to measure outcome; second, our patients were drawn from secondary referrals making them prone to the biases of such referrals.

All children had some disruption of schooling and peer interactions. School absence seemed catastrophic at the time. As adults, however, only two cases believed that their childhood CFS significantly affected their overall academic achievement or caused social isolation to persist into adulthood. We would discourage home tuition and aim for a return to school as soon as possible.

The symptoms of childhood and adult CFS were similar (Dowsett et al, 1990). Childhood sufferers graduating into adults with CFS maintained the same pattern of symptoms. No physical illness was subsequently diagnosed in individuals which could have accounted for the original symptom presentation.

All children making total recoveries were fully engaged in therapy, while all those describing significant symptoms remained unengaged. This has also been reported by other workers and reaffirms the critical importance of successfully engaging with both the patients and family (Vereker, 1992).

All those responding to the question felt that their symptoms were not believed by medical staff and that the treatments suggested were of little use. They reported psychiatric involvement to be unhelpful and unsympathetic. Indeed, the report by the three Royal Colleges emphasises the counterproductive distortion of the doctorpatient relationship in CFS (Royal Colleges of Physicians, Psychiatrists and General Practitioners, 1996). As the overall prognosis is good in those accepting therapy, it is vital to identify relevant factors promoting this acceptance. Particularly important is the need to be sensitive to the initial contact with psychiatric services. One must validate the child's complaints and explore family and psychosocial issues with tact.

In two cases depressive symptomatology was currently present, both being treated with antidepressants. An association exists between CFS in childhood and psychiatric disorder (Walford et al, 1993). This has also been frequently documented in adults with CFS where one-half to two-thirds of patients have a comorbid psychiatric illness, most often depression, anxiety or somatoform disorders (David, 1991). It has been suggested that the depressed mood may be reactive to the chronic physical symptoms in CFS. However, this has not been supported by a study comparing depressive symptomatology in children with CFS to those suffering the chronic physical illness of cystic fibrosis (Walford et al, 1993). Even if reactive, untreated depressive symptoms can become chronic and disabling (Lynch, 1994).

In the majority of cases CFS is a mild selflimiting disorder, with sufferers in primary care having less intense illness beliefs (Sidebotham et al, 1994). However, it is becoming increasingly recognised in children and can be a devastating illness. Our study is important because it shows that even in severe cases the outcome is good if managed effectively. Larger-scale prospective studies are required to provide accurate information on outcome and to help delineate prognostic factors. A successful doctor-patient relationship is necessary to ensure compliance with management plans and sufferers must feel that their illness is believed.

\section{References}

BONNER, D., Ron, M., Chalder, T., et al (1994) Chronic fatigue syndrome: a follow up study. Journal of Neurology. Neurosurgery and Psychiatry. 57, 617-621.

Butler, S., Chalder, T., Ron, M., et al (1991) Cognitive behaviour therapy in chronic fatigue syndrome. Journal of Neurology. Neurosurgery and Psychiatry. 54. 153-158.

Cleare, A. J. \& Wessely, S. (1996) Chronic fatigue syndrome: An update. Journal of Continuing Education for General Practitioners, 14 August, 61-69.

DAVID, A. S. (1991) Postviral fatigue syndrome and psychiatry. British Medical Bulletin, 47, 966-988.

-. Wessely, S. \& PELOSI, A. J. (1988) Postviral fatigue syndrome: time for a new approach. British Medical Joumal, 296, 696-699.

- \& WESSELY, S. (1993) Chronic fatigue, ME and ICD-10. Lancet, 342, 1247-1248.

Deale, A., Chalder, T., Marks, I., et al (1997) Cognitive behaviour therapy for chronic fatigue syndrome: a randomised controlled trial. American Journal of Psychiatry. 154, 408-414.

DOWSETT, E. G. RAMSEY, A. M. \& MCCARTNEY, R. A. (1990) Myalgic encephalomyelitis - a persistent enteroviral infection? Postgraduate Medical Journal, 66, 526-530.

FEDER, H. M., DWORKIN, P. H. \& ORKIN, C. (1994) Outcome of 48 paediatric patients with chronic fatigue: a clinical experience. Archives of Family Medicine, 3. 1049-1055.

FuKUDA, K., STRAuS, S., HickIE, I., et al (1994) The chronic fatigue syndrome: a comprehensive approach to its definition and study. Annals of Internal Medicine, 121. 953-959.

FULCHER, K. Y. \& WHITE, P. D. (1997) Randomised controlled trial of graded exercise in patients with the chronic fatigue syndrome. British Medical Journal 314, 1647-1652.

HARRIS, F. \& TATT, L. (1989) Damaging diagnoses of myalgic encephalitis in children. British Medical Journal, 299. 790. 
Hinds, G. M. R. \& McCluskeY, D. R. M. (1993) A retrospective study of the chronic fatigue syndrome. Proceedings of the Royal College of Physicians of Edinburgh, 23, 10-14.

JOYCE. J., HOTOPF, M. \& WESSELY, S. (1997) The prognosis of chronic fatigue and chronic fatigue syndrome: a systematic review. Quarterly Journal of Medicine, 80. 223-233.

Kennedy, J. L. \& PeARCE, J. B. (1995) Chronic fatigue syndrome in childhood. Current Opinion in Psychiatry. 8. 231-234.

LASK, B. \& DILLON. J. J. (1990) Postviral fatigue syndrome. Archives of Disease in Childhood, 65. 1198.

LYNCH. S. (1994) Chronic fatigue syndrome. Advances in Psychiatric Treatment, 1, 33-40.

Royal Colleges of Physicians, Psychiatrists and General PRACTITIONERS (1996) Chronic fatigue sydrome: report of a Committee of the Royal College of Physicians, Royal College of Psychiatrists and Royal College of General Practitioners, London. Royal College of Physicians, 10. 29-30.

Sidebotham, P. D., Skeldon, I., Chambers, T. G., et al (1994) Refractory chronic fatigue syndrome in adolescence. British Journal of Hospital Medicine, 3. 110-112.
VEREKER, M. (1992) Chronic fatigue syndrome: a joint paediatric-psychiatric approach. Archives of Disease in Childhood, 67, 550-555.

WALFORD, G. A., MCNeLSON, W. \& MCCluskeY, D. R. (1993) Fatigue, depression and social adjustment in chronic fatigue syndrome. Archives of Disease in Childhood. 68. 384-385.

Wessely, S. (1995) The epidemiology of chronic fatigue syndrome. Epidemiological Review, 17, 139-151.

-. DAVID, A., BuTLER, S., et al (1989) Management of chronic (postviral) fatigue syndrome. Joumal of the Royal College of General Practitioners, 39. 26-29.

WiLson, A., HICKIE, I., LLOYD, A., et al (1994) Longitudinal study of outcome of chronic fatigue syndrome. British Medical Journal, 308, 756-759.

*Shakil S. Khawaja, Registrar in Child and Adolescent Psychiatry, and Pieter Van Boxel, Consultant Child and Adolescent Psychiatrist, West Berkshire Priority Care Services NHS Trust, Department of Child and Adolescent Psychiatry, 3 Craven Road, Reading RG1 5LF

*Correspondence

\section{Chronic Fatigue Syndrome}

\section{CR54}

Chronic fatigue syndrome is a debilitating condition affecting young and old of any social group and occupation. It is the expression of the interplay of physical and psychological factors and therefore needs to be treated with a joint medical and psychological approach, requiring sympathy and understanding not only from health professionals but also from the sufferer's relatives and employers, and from officialdom.

This report, prepared at the request of the Chief Medical Officer, aims to provide the information necessary for knowledge-based care and indicates whatfacilities and service provisions are required for the management of CFS in primary health care. The report also points to the need for well-defined research endeavours and clinical trials and includes a summary for commissioners of health care.

Price $\mathbf{1 0 . 0 0}$ Co-published with the Royal College of General Practitioners

For a full list of College Reports and Occasional Papers, please contact: Book Sales, Royal College of Psychiatrists, 17 Belgrave Square, London SW1X 8PG (Tel. +44(0)171 235 2351, extension 146).

The latest information on College publications is available on the INTERNET at: http://www.rcpsych.ac.uk

\section{Gaskell/Royal College of Psychiatrists}

